\title{
Basic fibroblast growth factor induces cholangiocarcinoma cell migration via activation of the MEK1/2 pathway
}

\author{
SIRILUCK NARONG $^{1}$ and KAWIN LEELAWAT ${ }^{2,3}$ \\ ${ }^{1}$ Division of Research and Technology Assessment, Department of Academic Support; \\ ${ }^{2}$ Department of Surgery, Rajavithi Hospital; ${ }^{3}$ College of Medicine, Rangsit University, Bangkok, Thailand
}

Received March 3, 2011; Accepted June 15, 2011

DOI: $10.3892 / \mathrm{ol} .2011 .333$

\begin{abstract}
The purpose of this study was to investigate the roles played by basic fibroblast growth factor (bFGF) in the induction of cholangiocarcinoma cell progression and to identify the signal transduction molecules that are activated by bFGF in cholangiocarcinoma cells. FGF receptor-2 (FGFR2) was shown to be expressed in two cholangiocarcinoma cell lines (RMCCA1 and KKU-100). Samples from RMCCA1 and KKU-100 were assayed for the mRNA. Phosphorylation levels were determined by Western blotting. Treatment of the cholangiocarcinoma cells with bFGF enhanced signaling via the phosphorylation of MEK1/2, induced cholangiocarcinoma cell migration and resulted in high levels of actin polymerization. Moreover, treatment with a MEK1/2 inhibitor (U0126) attenuated the effect of bFGF-induced cholangiocarcinoma cell migration. Taken together, these observations indicate that bFGF enhances the migration of cholangiocarcinoma cells and that this enhancement is regulated by the phosphorylation of MEK1/2.
\end{abstract}

\section{Introduction}

Cholangiocarcinoma is a cancer that arises from the bile duct epithelium and is one of the most common causes of cancer mortality in Thailand (1). This high mortality rate is due to the strong tendency of cholangiocarcinoma to be locally and distantly invasive. The curative treatment of choice is surgery with R0 resection, and there is no effective chemotherapeutic treatment for this type of cancer (2). Therefore, an understanding of the underlying mechanisms combined with the identification of new molecular markers involved in the regulation of its metastatic process are essential for the development of novel modalities to treat cholangiocarcinoma patients and improve their survival rates.

A previous study demonstrated that basic fibroblast growth factor (bFGF) is involved in the induction of the invasive

Correspondence to: Dr Kawin Leelawat, Department of Surgery, Rajavithi Hospital, Bangkok 10400, Thailand

E-mail: kawin.leelawat@gmail.com

Key words: cholangiocarcinoma, basic fibroblast growth factor, cell migration phenotype of cancer cells. Recently, bFGF was shown to activate the PI-3K and p38 MAPK pathways, which help to increase vascularization and enhance the aggressiveness of cancer cells (3). Multiple observations suggest that bFGF serves as a useful prognostic indicator for a number of cancer types including gastric (4), lung (5) and endometrial cancer (6).

Previously, it was demonstrated that bile samples from cholangiocarcinoma patients have higher levels of bFGF than those from normal patients, indicating that the overexpression of bFGF may be crucial for the carcinogenesis of cholangiocarcinoma (7). However, the roles of bFGF in cholangiocarcinoma cell progression have yet to be investigated. Therefore, the purpose of this study was to investigate the roles played by bFGF in the progression of cholangiocarcinoma and to identify the signal transduction molecules that are activated by bFGF in cholangiocarcinoma cells.

\section{Materials and methods}

Cell cultures. Two human cholangiocarcinoma cell lines were used in this study: RMCCA1, which is derived from a peripheral cholangiocarcinoma patient (8), and KKU-100, which is derived from a hilar cholangiocarcinoma patient (9). Cells were grown in Ham's F12 medium supplemented with $10 \%$ fetal bovine serum at $37^{\circ} \mathrm{C}$ in a $5 \% \mathrm{CO}_{2}$ humidified atmosphere. For the signal transduction experiments, the cells were starved overnight in serum-free medium.

Detection of FGFR expression. After being cultured for $12 \mathrm{~h}$, the cholangiocarcinoma cells were collected for the isolation of RNA. Total RNA was extracted using the RNeasy mini kit (Qiagen, GmbH, Germany) according to the manufacturer's instructions. RNA integrity was confirmed by absorption at 260 and $280 \mathrm{~nm}$ using a spectrophotometer (Beckman Coulter $\mathrm{Du}^{\circledR} 800$, Fullerton, CA, USA). Total RNA was then reversetranscribed using random primers and the iScript ${ }^{\mathrm{TM}} \mathrm{cDNA}^{\mathrm{m}}$ synthesis kit (Bio-Rad, Hercules, CA, USA) according to the manufacturer's instructions. The expression of the FGFR 1 and FGFR2 genes was analyzed using specific primers (Table I). The housekeeping gene glyceraldehyde 3-phosphate dehydrogenase (GAPDH) was used as an internal control to normalize variations in the integrity and total amount of cDNA. RT-PCR assays were performed in triplicate on the Chromo4 ${ }^{\mathrm{TM}}$ System (MJ Opticon Monitor, version 3.1, Bio-Rad, Hercules, CA, 
Table I. Primer sequences for RT-PCR.

\begin{tabular}{lllc}
\hline Gene & \multicolumn{1}{c}{ Forward } & \multicolumn{1}{c}{ Reverse } & Length (bp) \\
\hline FGFR1 & TAATGGACTCTGTGGTGCCCTC & ATGTGTGGTTGATGCTGCCG & 81 \\
FGFR2 & CGCTGGTGAGGATAACAACACG & TGGAAGTTCATACTCGGAGACCC & 80 \\
GAPDH & TGCACCACCAACTGCTTAGC & GGCATGGACTGTGGTCATGAG & 87 \\
\hline
\end{tabular}

A

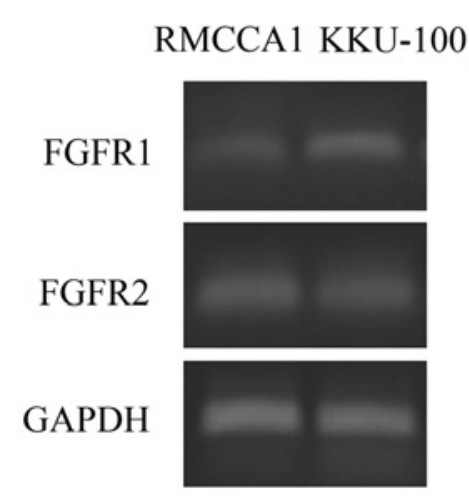

B

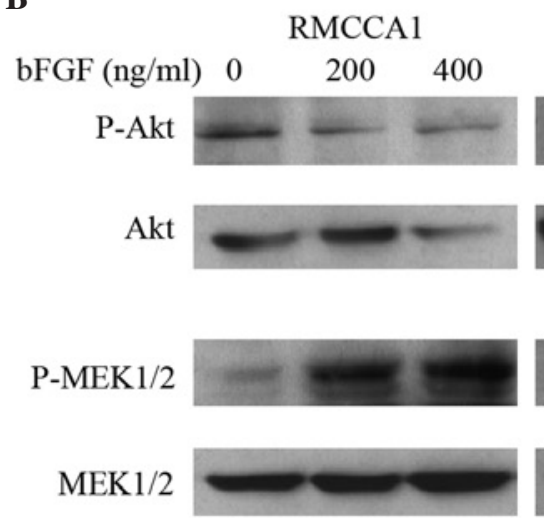

KKU-100

$0 \quad 200 \quad 400$
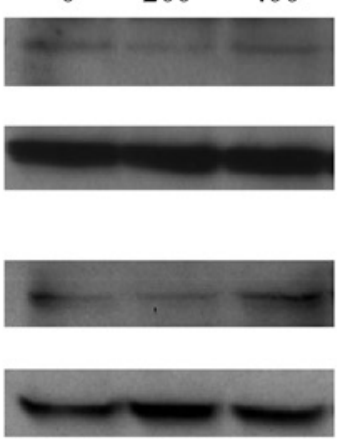

Figure 1. (A) Expression of FGFR1 and FGFR2 in cholangiocarcinoma cell lines. Samples from RMCCA1 and KKU-100 cells were assayed for the expression of FGFR1 and FGFR2 mRNA. GAPDH was used as a loading control. The two cell lines expressed the correct 81 and 80 -bp RT-PCR products for the FGFR1 and FGFR2 genes. (B) Phosphorylation of Akt and MEK1/2 in RMCCA1 and KKU-100 cells following bFGF treatment. RMCCA1 and KKU-100 cells were treated with bFGF at concentrations ranging from 0 to $400 \mathrm{ng} / \mathrm{ml}$ for $12 \mathrm{~h}$. Phosphorylation levels were determined by Western blotting. Total Akt and MEK1/2 were used as loading controls. The results are representative of three independent experiments is shown.

USA). The amplification conditions were $20 \mathrm{~min}$ at $50^{\circ} \mathrm{C}$, followed by $42 \mathrm{PCR}$ cycles $\left(15 \mathrm{sec}\right.$ at $94^{\circ} \mathrm{C}$ for denaturation; $30 \mathrm{sec}$ at $60^{\circ} \mathrm{C}$ for annealing; and $30 \mathrm{sec}$ at $72^{\circ} \mathrm{C}$ for extension). The PCR products were detected by $1.5 \%$ agarose gel electrophoresis.

Cell proliferation assay. The cholangiocarcinoma cells were seeded in 96-well culture plates at a density of 10,000 cells per well, followed by the addition of bFGF at various concentrations (0-400 ng/ml). The cells were then incubated for $48 \mathrm{~h}$ prior to adding the WST-1 cell proliferation assay reagent (Roche Diagnostics, Laval, Quebec, Canada) according to the manufacturer's instructions. The percentage of proliferation was calculated based on the number of untreated cells.

Cell migration assay. The migration of cholangiocarcinoma cells was assayed using a chamber with $8-\mu \mathrm{m}$ pore filters (Transwell, 24-well cell culture, Coster, Boston, MA, USA). The cholangiocarcinoma cells were added to the upper chamber, followed by the addition of bFGF at various concentrations. The chambers were incubated for $12 \mathrm{~h}$ at $37^{\circ} \mathrm{C}$. Following the incubation, the filters were fixed and stained with hematoxylin and the cells in five random high-power fields were counted under a light microscope.

Detection of actin polymerization. The cholangiocarcinoma cells were treated with or without $10 \mu \mathrm{M}$ U0126, and then with bFGF at concentrations of 0 (vehicle only) or $400 \mathrm{ng} / \mathrm{ml}$ for $24 \mathrm{~h}$. The cells were fixed with $4 \%$ paraformaldehyde, permeabilized in $1 \%$ Triton $\mathrm{X}-100$ for $15 \mathrm{~min}$ and blocked with $1 \%$ BSA. The cells were exposed to Alexa fluor 488 phalloidin (Molecular Probes, Eugene, OR, USA) for $30 \mathrm{~min}$ and washed with phosphate-buffered saline (PBS). Coverslips were mounted on the slide-glass containing the fixed cells using glycerol in TTBS. The slides were then examined under a fluorescent microscope (Olympus SV1000).

Statistical analysis. The experiments were performed in triplicate, and each result is reported as the mean \pm SD. Data between three or more groups were compared using the one-way analysis of variance, followed by the Dunnett's post hoc test. $\mathrm{P}<0.05$ was considered to be statistically significant.

\section{Results}

Expression of FGFR1 and FGFR2 in cholangiocarcinoma cells. We first investigated the expression of FGFR1 and FGFR2 in two human cholangiocarcinoma cell lines, RMCCA1 and KKU-100. The two cell lines expressed high levels of FGFR1 and FGFR2 mRNA (Fig. 1A).

Effects of bFGF on cholangiocarcinoma cell signaling. Previous studies demonstrated that activation of FGF receptors with bFGF induced the phosphorylation of the Akt and MEK1/2 pathways (10). Cholangiocarcinoma cells were treated with bFGF at concentrations ranging from 0 to $400 \mathrm{ng} / \mathrm{ml}$ for $24 \mathrm{~h}$, followed by Western blot analysis. In the RMCCA1 cells, the levels of phosphorylated MEK1/2, 
A

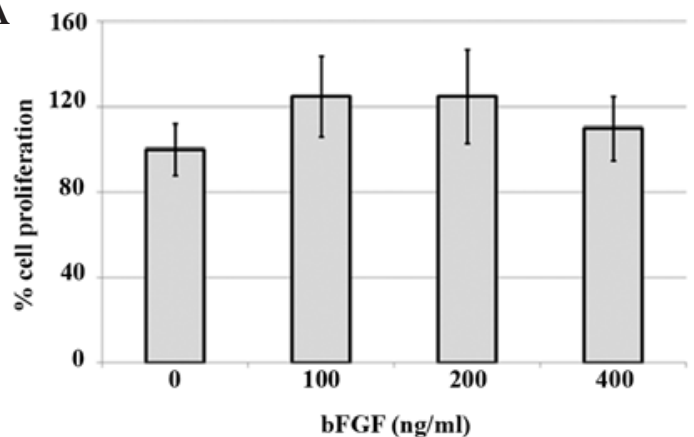

B

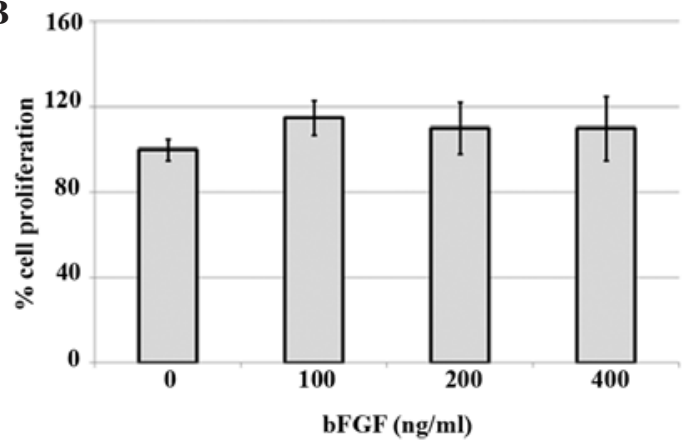

Figure 2. Effects of bFGF on (A) RMCCA1 and (B) KKU-100 cell proliferation. The cells were treated with bFGF at various concentrations for $48 \mathrm{~h}$. The effect of bFGF on cell proliferation was measured by WST-1 and analyzed by spectrophotometry (absorbance at $450 \mathrm{~nm}$ ). The results are reported as a percentage of cell proliferation, in which the optical density value from vehicle-treated cells was set at $100 \%$. The results are represented by the mean \pm SD of three independent experiments.

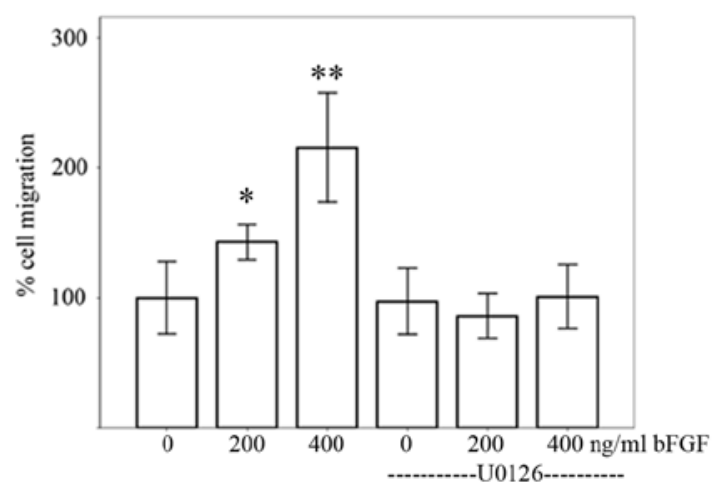

B

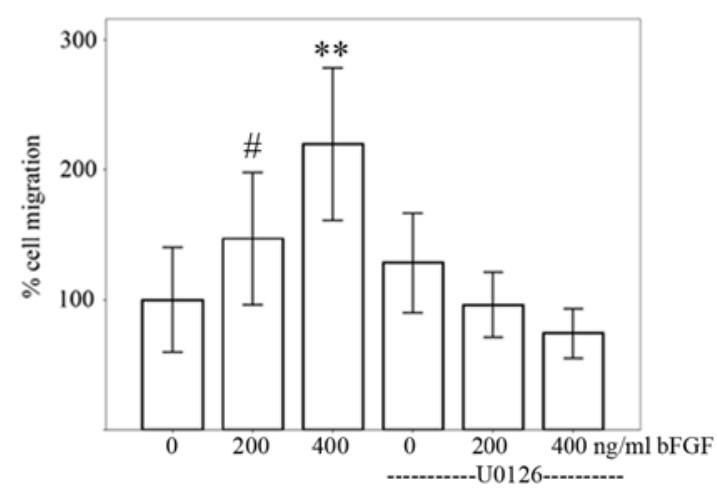

Figure 3. Effect of bFGF on in vitro cell migration in (A) RMCCA1 and (B) KKU-100 cell lines. Cells were pretreated with or without $10 \mu \mathrm{M}$ U0126 for $1 \mathrm{~h}$. Cells were then seeded onto the upper chamber of the Transwell and treated with $0-400 \mathrm{ng} / \mathrm{ml} \mathrm{bFGF}$. The data are shown as the mean \pm SD of three independent experiments that compare the number of cells that migrate (significant as compared with control: ${ }^{*} \mathrm{p}=0.04,{ }^{* *} \mathrm{p}<0.001$ and ${ }^{\#} \mathrm{p}=0.19$ ).

but not those of phosphorylated Akt, increased following the 200 and $400 \mathrm{ng} / \mathrm{ml}$ bFGF treatment. In the KKU-100 cells, a slight increase in the levels of phosphorylated MEK1/2 was only observed following the $400 \mathrm{ng} / \mathrm{ml} \mathrm{bFGF}$ treatment (Fig. 1B).

Effects of bFGF on cholangiocarcinoma cell proliferation. bFGF has been shown to stimulate cancer cell proliferation (11). In the present study, a WST-1 assay was used to determine whether bFGF had any effect on the proliferation rate of cholangiocarcinoma cells. RMCCA1 and KKU-100 cells were treated with bFGF at concentrations of $0,100,200$ and $400 \mathrm{ng} / \mathrm{ml}$ for two days. The assay results showed that there was no significant difference in the proliferation rate of cells treated with bFGF and that of control cells treated with PBS (RMCCA1; $\mathrm{p}=0.057$ and KKU-100, p=0.339) (Fig. 2).

Effects of bFGF on cell migration. Recent findings showed that $\mathrm{bFGF}$ is capable of stimulating cancer cell migration (12). To determine the effects of bFGF on the migration of RMCCA1 and KKU-100 cells, these cholangiocarcinoma cell lines were treated with bFGF at concentrations ranging from 0 to $400 \mathrm{ng} / \mathrm{ml}$ and then examined using a cell migra- tion assay. The percentage of cell migration when the cells were treated with the vehicle (PBS) was set at $100 \%$. The percentage of RMCCA1 cell migration was significantly increased when the cells were treated with 200 and $400 \mathrm{ng} / \mathrm{ml}$ of bFGF $(143.9 \pm 13.73 \%, p=0.04$ and $215.6 \pm 41.87 \%$; $<<0.001$, respectively). The percentage of KKU-100 cell migration was significantly increased in cells treated with $400 \mathrm{ng} / \mathrm{ml}$ of bFGF (220.0 $\pm 58.61 \%$ at $400 \mathrm{ng} / \mathrm{ml} \mathrm{bFGF;} \mathrm{p<0.001)} \mathrm{(Fig.} \mathrm{3).}$

Effects of a MEK1/2 inhibitor on bFGF-induced cholangiocarcinoma cell migration. To determine whether the activation of bFGF and its subsequent activation of MEK1/2 signaling are required for cholangiocarcinoma cell migration, the phosphorylation of MEK1/2 was inhibited using U0126, a MEK1/2-specific inhibitor. To evaluate cell migration, RMCCA1 and KKU-100 cells were treated with $10 \mu \mathrm{M}$ U0126, followed by treatment with bFGF. The cell migration induced by bFGF was inhibited by the U0126 treatment in the two cholangiocarcinoma cell lines (Fig. 3).

Effects of bFGF on the actin cytoskeleton of cholangiocarcinoma cells. RMCCA1 cells were stained with phalloidin to detect actin polymerization. Serum-starved cells showed 


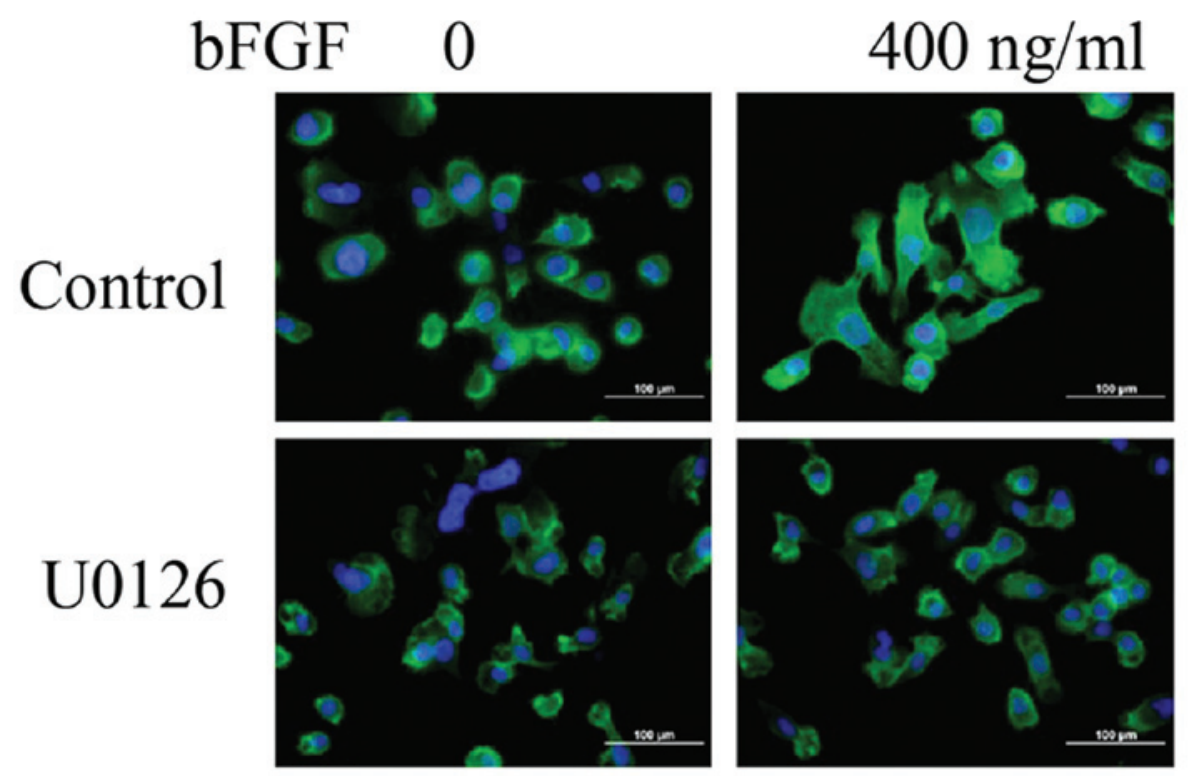

Figure 4. Effect of bFGF and U0126 on the actin cytoskeleton in RMCCA1 cells. RMCCA1 cells were pretreated with or without U0126, and then treated with 0 or $400 \mathrm{ng} / \mathrm{ml}$ bFGF. The cells were stained with Alexa Fluor 488 phalloidin to visualize the actin cytoskeleton.

low levels of actin polymerization. Following treatment with $400 \mathrm{ng} / \mathrm{ml}$ bFGF, cholangiocarcinoma cells exhibited high levels of actin polymerization in the periphery of the cells and the formation of distinct filopodia and lamellipodia. Treatment of the cholangiocarcinoma cells with $10 \mu \mathrm{M}$ U0126, prior to the addition of bFGF, eradicated the actin polymerization and decreased filopodia and lamellipodia formation (Fig. 4).

\section{Discussion}

bFGF and its receptors are involved in the process of normal cell growth, survival, differentiation, angiogenesis and cell migration during organogenesis (13-15). Recent studies have implicated bFGF in the metastasis of numerous types of cancer $(12,16)$. In the present study, the effect of bFGF on two cholangiocarcinoma cell lines was tested in vitro using cell proliferation and cell migration assays. The results demonstrated that stimulation of FGFR with bFGF promotes cancer cell migration, but not proliferation, in two cholangiocarcinoma cell lines.

A recent study found that actin organization is key to the formation of filopodia and lamellipodia, which in turn are implicated in the enhancement of cancer cell migration (17). In this study, the treatment of cholangiocarcinoma cells with bFGF increased actin polymerization formation and cell migration. These findings are consistent with a previous study demonstrating that bFGF induced stress fiber formation in cancer cells (18). Taken together, these observations suggest that bFGF induces cholangiocarcinoma cell migration via the regulation of actin organization.

bFGF has been found to induce FGFR dimerization, leading to activation of the PI3K/Akt and MEK1/2 pathways (10). The results of this study, however, suggested that these events involve the activation of the MEK1/2, but not the PI3K/Akt pathway. This assertion is based on the finding that bFGFtreated RMCCA1 and KKU-100 cells show dose-dependent increases in the levels of induced phosphorylated MEK1/2 but not in those of phosphorylated Akt. In addition, the inhibition of MEK1/2 by U0126 suppressed the migration of cholangiocarcinoma cells treated with bFGF. These results are consistent with a recent study that demonstrated the activation of the p44/p42 MAPK pathway, but not the Akt or STAT pathways, following bFGF stimulation (19). To the best of our knowledge, this is the first study to demonstrate the signal transduction pathways of $\mathrm{bFGF/FGFR} \mathrm{in} \mathrm{cholangiocarcinoma}$ cells. Previous studies also showed that activation of c-met, a hepatocyte growth factor receptor, or CXCR4 was capable of inducing cholangiocarcinoma cell migration via the activation of the MEK1/2 signaling pathway $(20,21)$. Therefore, we suggest that MEK $1 / 2$ is the central signaling pathway for the control of cholangiocarcinoma cell migration.

Although bFGF has been indicated as a potent stimulator of small-cell lung cancer cell proliferation (11), the results of this study suggest otherwise. This study showed that bFGF had no direct effect on the cell proliferation of cholangiocarcinoma cell lines. This disparity may be a result of the activation of various downstream pathways of bFGF/FGFR. The increased cell proliferation may require PI3K/Akt and MEK1/2 activation. Further studies should be performed to clarify the roles that the PI3K/Akt and MEK1/2 pathways play in cell proliferation following bFGF stimulation.

In conclusion, in this study, bFGF was shown to play a significant role in the cholangiocarcinoma cell lines RMCCA1 and KKU-100. The treatment of cholangiocarcinoma cells with bFGF significantly increased in vitro migration without affecting cell proliferation. In addition, the phosphorylation of MEK1/2 was increased, whereas the phosphorylation of Akt was not affected. Finally, inhibition of MEK1/2 phosphorylation with U0126 significantly decreased cancer cell migration following stimulation with bFGF. These findings suggest that $\mathrm{bFGF}$ induces the migration of cholangiocarcinoma cells via the activation of MEK1/2 signaling and the subsequent stimulation of actin polymerization. Inhibition of the bFGF/FGFR and MEK1/2 pathways may therefore be a potential novel approach for the treatment of cholangiocarcinoma. 


\section{Acknowledgements}

This study was supported by the Rajavithi Hospital Fund.

\section{References}

1. Sripa B and Pairojkul C: Cholangiocarcinoma: lessons from Thailand. Curr Opin Gastroenterol 24: 349-356, 2008.

2. Blechacz BRA and Gores GJ: Cholangiocarcinoma. Clin Liver Dis 12: 131-150, 2008.

3. Fontijn D, Bosch LJ, Duyndam MC, van Berkel MP, Janmaat ML and Boven E: Basic fibroblast growth factor-mediated overexpression of vascular endothelial growth factor in 1F6 human melanoma cells is regulated by activation of PI-3K and p38 MAPK. Cell Oncol 31: 179-190, 2009.

4. Zhang W, Chu YQ, Ye ZY, Zhao ZS and Tao HQ: Expression of hepatocyte growth factor and basic fibroblast growth factor as prognostic indicators in gastric cancer. Anat Rec (Hoboken) 292 $1114-1121,2009$

5. Massabeau C, Rouquette I, Lauwers-Cances V, et al: Basic fibroblast growth factor-2/beta3 integrin expression profile: signature of local progression after chemoradiotherapy for patients with locally advanced non-small-cell lung cancer. Int J Radiat Oncol Biol Phys 75: 696-702, 2009.

6. Dai H, Zhao S, Xu L, Chen A and Dai S: Expression of Efp, VEGF and bFGF in normal, hyperplastic and malignant endometrial tissue. Oncol Rep 23: 795-799, 2010.

7. Su WC, Shiesh SC, Liu HS, Chen CY, Chow NH and Lin XZ: Expression of oncogene products HER2/Neu and Ras and fibrosis-related growth factors bFGF, TGF-beta, and PDGF in bile from biliary malignancies and inflammatory disorders. Dig Dis Sci 46: 1387-1392, 2001.

8. Rattanasinganchan $\mathrm{P}$, Leelawat $\mathrm{K}$, Treepongkaruna SA, et al: Establishment and characterization of a cholangiocarcinoma cell line (RMCCA-1) from a Thai patient. World J Gastroenterol 12: 6500-6506, 2006.

9. Sripa B, Leungwattanawanit S, Nitta T, et al: Establishment and characterization of an opisthorchiasis-associated cholangiocarcinoma cell line (KKU-100). World J Gastroenterol 11: 3392-3397, 2005.
10. Turner $\mathrm{N}$ and Grose R: Fibroblast growth factor signalling: from development to cancer. Nat Rev Cancer 10: 116-129, 2010.

11. Pardo OE, Latigo J, Jeffery RE, et al: The fibroblast growth factor receptor inhibitor PD173074 blocks small cell lung cancer growth in vitro and in vivo. Cancer Res 69: 8645-8651, 2009.

12. Nomura S, Yoshitomi H, Takano S, et al: FGF10/FGFR2 signal induces cell migration and invasion in pancreatic cancer. Br J Cancer 99: 305-313, 2008.

13. McMahon A, Reeves GT, Supatto W and Stathopoulos A: Mesoderm migration in Drosophila is a multi-step process requiring FGF signaling and integrin activity. Development 137: 2167-2175, 2010.

14. Ozkan S, Vural B, Dalcik C, Tas A and Dalcik H: Placental expression of insulin-like growth factor-I, fibroblast growth factor-basic and neural cell adhesion molecule in pregnancies with small for gestational age fetuses. J Perinatol 28: 468-474, 2008.

15. Korc M and Friesel RE: The role of fibroblast growth factors in tumor growth. Curr Cancer Drug Targets 9: 639-651, 2009.

16. Sato T, Oshima T, Yoshihara $\mathrm{K}$, et al: Overexpression of the fibroblast growth factor receptor-1 gene correlates with liver metastasis in colorectal cancer. Oncol Rep 21: 211-216, 2009.

17. Vignjevic D and Montagnac G: Reorganisation of the dendritic actin network during cancer cell migration and invasion. Semin Cancer Biol 18: 12-22, 2008.

18. Abe M, Inoue D, Matsunaga K, et al: Goniodomin A, an antifungal polyether macrolide, exhibits antiangiogenic activities via inhibition of actin reorganization in endothelial cells. J Cell Physiol 190: 109-116, 2002.

19. Puhr M, Santer FR, Neuwirt H, Marcias G, Hobisch A and Culig Z: SOCS-3 antagonises the proliferative and migratory effects of fibroblast growth factor-2 in prostate cancer by inhibition of p44/p42 MAPK signalling. Endocr Relat Cancer 17: 525-538, 2010

20. Leelawat K, Leelawat S, Narong $S$ and Hongeng S: Roles of the MEK1/2 and AKT pathways in CXCL12/CXCR4 induced cholangiocarcinoma cell invasion. World J Gastroenterol 13: $1561-1568,2007$

21. Leelawat K, Leelawat S, Tepaksorn P, et al: Involvement of c-Met/hepatocyte growth factor pathway in cholangiocarcinoma cell invasion and its therapeutic inhibition with small interfering RNA specific for c-Met. J Surg Res 136: 78-84, 2006. 